\title{
EVALUATION OF THE CONDITIONS OF EFFECTIVE LOGISTIC STRATEGY IMPLEMENTATION OF AN ENTERPRISE ON THE BASIS OF FUNCTIONAL AND COST ANALYSIS
}

\author{
Vasyl Shvets ${ }^{1}$, Hanna Baranets ${ }^{2}$, Olena Tryfonova ${ }^{3}$
}

\begin{abstract}
In the context of the current dynamic environment, the complexity of socio-economic objects stipulates the increased requirements for their analysis. The field of strategic logistic management is not an exception. The logistic potential is considered as a control object. Formation elements of the potential determine the conditions for the successful implementation of the selected logistic strategy of an enterprise. The potential of managerial logistic personnel, technological personnel, logistic infrastructure, product and technological innovations in logistics, marketing research, organizational and transfer potential are considered as logistic potential elements. Problems concerning substantiation of logistic strategy selection, determination of the internal conditions to provide its efficient implementation, as well as quantitative measurement of the conditions, are still unstudied. The purpose of the paper is to carry out functional and cost analysis (FCA) of logistic potential elements of an enterprise to estimate the correspondence of the internal conditions to the selected logistic strategy. Methodology. FCA as a method of research is used. The sequence of the FCA implementation and characteristic of its main stages are considered in the paper. Special attention is paid to expert assessments of the significance of logistic potential elements which are regarded as internal conditions for the strategic changes realization in the area of enterprise logistics. To do that, the paper applies techniques of priority ranking and pairwise comparisons. The consistency of the obtained results is proved statistically. Statistic factor of the relative range has been applied to characterize the dispersion of individual significances obtained for each logistic potential element. Results. The paper has developed a sequence of the FCA implementation with the characterization of its basic stages. There has been described preparatory, information, analytical, research, and recommendation stages. The proposed sequence matches a traditional concept of the FCA stages. However, their contents vary depending upon object specifics, identification of objectives and tasks of carrying out analysis. Value/originality. The results of the study in the form of the expert evaluation of the significance of the logistic potential elements give an opportunity to plan the costs connected with the introduction of strategic changes in the field of an enterprise logistics.
\end{abstract}

Key words: logistic potential, logistic strategy, functional and cost analysis, situational profile, logistic costs.

JEL Classification: C81, D78, M11

\section{Introduction}

In the context of the current dynamic environment, the complexity of socio-economic objects stipulates the increased requirements for their analysis. The field of strategic logistic management is not an exception. Consideration of logistic management at an enterprise helps to understand that provision of the best conditions (opportunities) for the effective implementation of the tendencies for long-term changes is one of its tasks. In this case, the logistic potential can be considered as a management object, as a potential of an enterprise to implement optimization logistic properties while

\footnotetext{
Corresponding author:

${ }^{1}$ National Technical University “Dnipro Polytechnic”, Ukraine.

E-mail: vasil-shvetc@ukr.net

${ }^{2}$ National Technical University “Dnipro Polytechnic”, Ukraine.

E-mail: anna270276@ua.fm

${ }^{3}$ National Technical University “Dnipro Polytechnic”, Ukraine.

E-mail: elenatriphonova@gmail.com
}

organizing a flow of material, financial, and information resources at the stages of production and logistic chain owing to integration capabilities to coordinate activities of functional subdivisions and availability of the providing conditions (i.e. staff, infrastructure, marketing etc.).

In the strategic context, determination of conditions for a successful implementation of the selected logistic strategy is the general function performed by the logistic potential. The content of specific functions is to concretize the conditions described by the specified behaviour of the logistic potential elements depending upon the type of a strategy selected by an enterprise (Figure 1). 


\begin{tabular}{|c|c|c|c|}
\hline \multirow{2}{*}{$\begin{array}{l}\text { Elements forming logistic } \\
\text { potential }\end{array}$} & \multicolumn{3}{|c|}{ Tendencies of changes in logistic potential elements } \\
\hline & increasing & stabilization & reduction \\
\hline $\begin{array}{l}\text { 1. Potential of managerial logistic } \\
\text { personnel }\end{array}$ & & & \\
\hline 2. Organizational potential & & & \\
\hline $\begin{array}{l}\text { 3. Potential of managerial } \\
\text { innovations }\end{array}$ & | & i & \\
\hline 4. Transfer potential & & i & \\
\hline $\begin{array}{l}\text { 5. Potential of logistic } \\
\text { infrastructure }\end{array}$ & & & \\
\hline $\begin{array}{l}\text { 6. Potential of technological } \\
\text { personnel }\end{array}$ & & & \\
\hline $\begin{array}{l}\text { 7. Potential of product and } \\
\text { technological innovations in } \\
\text { logistics }\end{array}$ & I & & i \\
\hline 8. Potential of marketing research & & & \\
\hline
\end{tabular}

Profile of cost minimization strategy Profile of diversification strategy

Profile of specialization strategy

Profile of logistic innovation strategy

Figure 1. Situational profiles of changes in logistic potential elements developed for the selected logistic strategy

Source: Baranets, 2016

Quantitative representation of the logistic potential elements importance can be obtained by means of functional and cost analysis (FCA) helping prevent making inefficient decisions concerning the formation of internal conditions to implement a logistic strategy of an enterprise.

\section{The state of research}

Academic studies in the field of strategic management of enterprise logistics are of rather stable content, for example, scientific works of the following authors: D. Waters (2009), V. Dybska et al. (2008), V. Sergeiev (2013), Ie. Krykavsky (2004). As a rule, studies determine the idea of logistics strategy, its tendencies, types, description of its development and implementation sequence, and estimation of external conditions. Certain studies such as J. R. Stock and Douglas M. Lambert (2005) concern the development of global logistic strategies, formation and development of strategic plans for supply chains logistics, and their certain links. At the same time, problems concerning substantiation of logistic strategy selection, determination of the internal conditions to provide its efficient implementation, as well as quantitative measurement of the conditions are still unstudied.

The paper is intended to carry out FCA analysis of potential elements of logistics to estimate the correspondence of the internal conditions to the selected logistic strategy. Within the framework of the organized analysis procedure, equivalent characteristics of the significance of the logistic potential elements and the expenditures connected with their formation should be determined.

\section{FCA application to evaluate logistic potential of an enterprise}

FCA is a technique of feasibility studies of systems aimed at optimizing the relations between their consumer properties and costs. Consumer properties of the object are determined by its usefulness that is an ability to meet certain needs. Taking into account the fact that FCA is orientated to detect the external manifestations of the properties of an object in a certain system of relations then a function is considered as the basic utility component manifests itself in the field of production and consumption. Therefore, the feature of the FCA is to identify a set of expedient functions, which should be performed by a research object under specific circumstances.

FCA feature is a clear performance sequence to be met in the context of any type of its implementation. In the opinion of Senchenko (2011), availability of strictly set action algorithm, as well as the opportunity for a researcher to demonstrate his/her creativity, i.e. to 
Table 1

The sequence to implement FCA logistic potential elements to estimate correspondence between the internal conditions and the selected strategy

\begin{tabular}{|c|c|c|}
\hline Stages & $\begin{array}{l}\text { Name of the stage according to } \\
\text { the selected object to be analysed }\end{array}$ & A brief description of the stage \\
\hline \multirow{3}{*}{ 1. Preparatory stage } & $\begin{array}{l}\text { Concretization of the object to be } \\
\text { analysed }\end{array}$ & $\begin{array}{l}\text { Logistic potential as a set of the elements, which certain changes create } \\
\text { conditions to implement a logistic strategy of an enterprise. }\end{array}$ \\
\hline & Identification of an objective & $\begin{array}{l}\text { Planning cost structure to create conditions for effective implementation of } \\
\text { logistics strategy. }\end{array}$ \\
\hline & Statement of the tasks & $\begin{array}{l}\text { Detailed evaluation of the conditions within "validity (significance) - cost" } \\
\text { format to ensure the efficient implementation of basic types of logistic strategies. }\end{array}$ \\
\hline \multirow[t]{2}{*}{ 2. Information stage } & \multirow{2}{*}{$\begin{array}{l}\text { Collection data of the object } \\
\text { under study }\end{array}$} & $\begin{array}{l}\text { Defining the logistic potential components; substantiating their significance } \\
\text { (functions) in the context of the necessity to form conditions for the logistic } \\
\text { strategy implementation; describing the dynamic characteristics. }\end{array}$ \\
\hline & & Identifying costs to form the logistic potential elements. \\
\hline \multirow[t]{2}{*}{ 3. Analytical stage } & $\begin{array}{l}\text { Evaluation of the functions } \\
\text { significance }\end{array}$ & $\begin{array}{l}\text { Expert evaluation of the logistic potential elements validity (significance) using } \\
\text { methods with the lowest subjectivity level, which provide a simultaneous high- } \\
\text { accuracy evaluation. }\end{array}$ \\
\hline & $\begin{array}{l}\text { Evaluation of the functions' } \\
\text { performance }\end{array}$ & $\begin{array}{l}\text { Evaluating the structure costs to form the logistic potential elements as of the } \\
\text { current date. }\end{array}$ \\
\hline 4. Research stage & $\begin{array}{l}\text { Construction of the combined } \\
\text { FCA diagram }\end{array}$ & $\begin{array}{l}\text { Graphical representation of a ratio between the logistic potential elements } \\
\text { validity (significance) and cost structure to form them as of the current date. } \\
\text { Identifying the logistics strategy type an enterprise is implementing or is capable } \\
\text { of implementing as of the current date. Determining the desirable strategic } \\
\text { tendency of changes in the context of the enterprise. } \\
\text { Matching the current and perspective evaluation results with the response to a } \\
\text { question "Do the formed conditions correspond to the objectives aimed at provision } \\
\text { of efficient implementation of the selected tendency of strategic changes?" }\end{array}$ \\
\hline $\begin{array}{l}\text { 5. Recommendation } \\
\text { stage }\end{array}$ & $\begin{array}{l}\text { Elaborating the } \\
\text { recommendations and measures } \\
\text { to eliminate the identified } \\
\text { disparities }\end{array}$ & $\begin{array}{l}\text { If the current cost structure cannot provide the necessary conditions of the } \\
\text { selected logistic strategy implementation over the following years, it is required } \\
\text { to schedule value of total costs to form the logistic potential of an enterprise and } \\
\text { to share them to the determined structure for the following year. }\end{array}$ \\
\hline
\end{tabular}

Source: the by authors

form independently a strategy to study while keeping procedure sequence of stages, makes it possible to expand FCA sphere.

Thus, the logistic potential of an enterprise is considered as an object of the FCA as a set of elements implementing functions to form conditions for the efficient implementation of a certain logistic strategy.

The paper has developed a sequence of FCA implementation; its basic stages have been characterized in brief (Table 1). The proposed sequence matches a traditional concept of the FCA stages; however, their contents vary depending upon object specifics, identification of objectives and tasks of carrying out analysis.

\section{Identification of logistic potential elements and costs for their formation}

Preparation stage determines object to be analysed. It was above mentioned that selection of the logistic potential as the object to be analysed is substantiated by means of its performance of functions intended to the provision of the enterprise logistic strategy implementation. The conditions are described by means of changes in the logistic potential elements as for the certain tendencies involving their quantitative evaluation.

FCA is a perspective analysis method; thus, setting its objective in the form of "a cost structure planning to ensure the effective logistics strategy implementation" corresponds to the peculiarity. Formulation of the tasks should be subordinated to the primary objective. It is to estimate specifically conditions in terms of validity (significance)-cost format to ensure the effective implementation of the basic types of logistic strategies.

In general, the idea of information stage is to collect data concerning the objectunderstudy; thus, step one of the stage is a determination of the logistic potential components, substantiation of their significance (functions) in the context of the necessity to create conditions for the logistics strategy implementation. The same step also describes dynamic characteristics of implementation conditions of basic types of logistic strategies. Determination of changes in the behaviour of logistic potential elements is meant, i.e. their modelling with the help of situational profiles development (Figure 1). 
Step two of the information stage identifies costs to form the logistic potential elements. The problem needs particular attention since it involves: first - the detailed structuring, and second - the improvement of methodological foundations to determine total value taking into account investment and innovative nature of certain types of logistic cost.

It is expedient to use for the step a technique to calculate total costs making it possible to compare both current and long-term investment logistic costs. According to the standard method, the total costs $\mathrm{Z}$ are defined as follows:

$$
Z=C+E I
$$

where $C$ is current production (prime) cost per unit; $I$ is a unit investment; and $E$ is a regulatory factor of the comparative effectiveness of the capital expenditures (cost-effectiveness ratio).

If innovative logistic expenditures are an investment into different (in terms of scientific and technological level) objects, then formula (1) should be adapted to the conditions of complete logistic costs formation and represented in a more correct form:

$$
Z_{L}=C_{i}+\sum_{i=1}^{n} E_{i} I_{i}
$$

where, $Z_{L}$ is the reduced logistic cost; $i$ is the ordinal number of objects of logistic innovations according to the scientific and technological level $(i=1 ; n) ; E_{i}$ is the regulatory factor depending upon the scientific and technological level of the object of logistic innovations; and $I_{i}$ is the investment in $i^{\text {th }}$ type object.

\section{Evaluation of the significance of logistic potential elements}

The next stage of the FCA is an analytical one, which general idea is to evaluate significance of the object functions and the expenditures connected with their performance. Export estimation is very important to evaluate the significance of the logistic potential elements. If so, S. Beshelev and F. Hurvich (2008) approve that experts fill largely quantitative information gaps.
Formation of the logistic potential can be considered as a function implemented by subfunctions meeting the conditions listed in Figure 1.

It is proposed to use a method of priority ranking (MPA) and a method of pairwise comparisons (MPC) for the expert estimation of the subfunctions significance.

In the context of method one, $m$-objects are selected (i.e. elements of the logistic potential formation). Changes in priority tendencies (decrease, stabilization, progress) have been identified for each of them. The tendencies are com compared in pairs with the use of priority signs $>$, <, and = indicating respectively the higher, lower and approximately equal importance of each element change to implement the selected strategy. Within the framework of each selected strategy, comparison system of the logistic potential elements is developed taking into consideration situational profile represented in Fig. 1. Then, the adjacency matrix to determine functional significance of each element of the logistic potential formation is developed on the basis of the obtained system. Considering the possibility that the elements of logistic potential can be changed in two directions from their constant state, as well as polar changes from their increasing state to reducing state or backward, the priority ratios can take values from 0 to 1.0 and from 1.0 to 2.0 with 0.5 step.

Table 2 demonstrates the adjacency matrix, which also contains intermediate calculation parameters and the final estimation of the functions significance.

MPC has also been used to determine relative significance of the logistic potential elements. Pairwise comparisons are shown in the form of advantage matrices where each $a_{i j}$ element is a priority level of function $u_{i}$ over $u_{j}(i, j=\overline{1, n})$. The expert work is in the fact that while performing a pairwise comparison of $a_{1}, \ldots, a_{n}$ factors, a table of paired comparisons should be filled. If the significance of $w_{1}, w_{2}, \ldots, w_{n}$ are unknown beforehand, then pairwise comparisons of elements are carried out with the use of subjective opinions quantifying on a scale numerically and then the problem of $w$ parameter determination is solved. 9-point Saaty's scale can be used as the estimation scale (Saaty, 2008).

Table 2

\begin{tabular}{|c|c|c|c|c|c|c|c|c|c|c|c|}
\hline \multirow{2}{*}{$\begin{array}{c}\text { Function } \\
\mathrm{F}_{\mathrm{i}}\end{array}$} & \multicolumn{8}{|c|}{ Function $F_{i}$} & \multirow{2}{*}{$\begin{array}{l}\text { Sum of values } \\
\text { in the line } U_{i}\end{array}$} & \multirow{2}{*}{$\begin{array}{c}\text { Absolute } \\
\text { priority } \mathrm{U}_{\mathrm{i}}\end{array}$} & \multirow{2}{*}{$\begin{array}{c}\text { Significance } \\
\mathrm{H}_{\mathrm{i}}\end{array}$} \\
\hline & $\mathrm{F}_{1}$ & $\mathrm{~F}_{2}$ & $\mathrm{~F}_{3}$ & $\mathrm{~F}_{4}$ & $\mathrm{~F}_{5}$ & $\mathrm{~F}_{6}$ & $\mathrm{~F}_{7}$ & $\mathrm{~F}_{8}$ & & & \\
\hline $\mathrm{F}_{1}$ & 1 & 1 & 1.5 & 1.5 & 1.5 & 1.5 & 2 & 2 & 12 & 87.5 & 0.200 \\
\hline $\mathrm{F}_{2}$ & 1 & 1 & 1.5 & 1.5 & 1.5 & 1.5 & 2 & 2 & 12 & 87.5 & 0.200 \\
\hline $\mathrm{F}_{3}$ & 0.5 & 0,5 & 1 & 1 & 1 & 1 & 1.5 & 1.5 & 8 & 55.5 & 0.127 \\
\hline $\mathrm{F}_{4}$ & 0.5 & 0,5 & 1 & 1 & 1 & 1 & 1.5 & 1.5 & 8 & 55.5 & 0.127 \\
\hline $\mathrm{F}_{5}$ & 0.5 & 0,5 & 1 & 1 & 1 & 1 & 1.5 & 1.5 & 8 & 55.5 & 0.127 \\
\hline $\mathrm{F}_{6}$ & 0.5 & 0,5 & 1 & 1 & 1 & 1 & 2 & 2 & 9 & 59.0 & 0.135 \\
\hline $\mathrm{F}_{7}$ & 0 & 0 & 0.5 & 0.5 & 0.5 & 0 & 1 & 1 & 3.5 & 19.0 & 0.042 \\
\hline $\mathrm{F}_{8}$ & 0 & 0 & 0.5 & 0.5 & 0.5 & 0 & 1 & 1 & 3.5 & 19.0 & 0.042 \\
\hline Total & & & & & & & & & & 438.5 & 1.0 \\
\hline
\end{tabular}

The adjacency matrix of the logistic potential elements formed to implement the cost minimization strategy

Source: the authors' calculations 
The range of the scale significance stages makes it possible to evaluate quantitatively the priority of a certain element of the logistic potential not only in terms of the changes fixed at the situational profile but also taking into account possible or more favourable deviations from the procedure. Such variations are evaluated via intermediate values in the Saaty's scale.

Matrix consistency or uniformity is an important issue while developing the pairwise comparisons matrix. Expert determines uniformity index (UI) or consistency ratio $(C R) . C R \leq 0.10$ is used as the allowable value. Its calculation is based on a comparison of calculated and tabulated values of the consistency index. If in the context of pairwise comparisons matrix $C R>0.1$, then significant disturbance of opinion logic takes place.

Matrices of pairwise comparisons of the logistic potential elements formed to implement basic types of logistic strategies are developed according to the abovementioned explanations. Then, the type of characteristic equations corresponding to the developed matrices, eigenvalues determined as the roots of the equations, maximum eigenvalue of matrix $\lambda_{\max }$, coordinates of the basic proper vector, index and uniformity ratio are determined.

The procedure of matrices of proper vectors is time-consuming; thus, it is subject to approximation. The method of geometric mean distance measurement between the factors (elements) under estimation is applied (Nikul, 2012).

Table 3 demonstrates results of the calculations according to the listed algorithms of accurate and approximate computations results for the strategy of cost minimization.

Data from Table 4 were used to estimate the consistency of the expert opinions. We can see from the results that the expert evaluations are sufficiently consistent no matter which method of the parameters calculation for pairwise comparison matrix will be selected.

Table 5 represents summarized calculation results of the significance of logistic potential elements depending upon the selected strategy; they were obtained with the help of the above-listed methods. A technique of the data averaging has been applied to obtain the resultative significance of each function (Figure 2).

Statistic factor of relative range $r_{i}$ has been applied to characterize the dispersion of individual significances obtained for the $i^{\text {th }}$ element. A researcher checks, if $r_{i} \leq 1$ condition is met. Table 6 demonstrates that consistency conditions are met.

Further implementation of the FCA at the analytical stage involves an evaluation of the cost structure related to the logistic potential formation during the current period within the use of the above-mentioned methodological recommendations.

Table 3

Evaluation of the significance of logistic potential elements formed to implement the cost minimization strategy

\begin{tabular}{|c|c|c|c|c|c|c|c|c|c|c|c|c|c|c|}
\hline \multirow{2}{*}{$\mathrm{F}_{\mathrm{i}}$} & \multicolumn{1}{|c|}{$\mathrm{F}_{1}$} & $\mathrm{~F}_{2}$ & $\mathrm{~F}_{3}$ & $\mathrm{~F}_{4}$ & $\mathrm{~F}_{5}$ & $\mathrm{~F}_{6}$ & $\mathrm{~F}_{7}$ & $\mathrm{~F}_{8}$ & $\begin{array}{c}\text { Proper } \\
\text { vector }\end{array}$ & $\begin{array}{c}\text { Normalized } \\
\text { proper } \\
\text { vector }\end{array}$ & $\lambda_{\max }$ & $\begin{array}{c}\text { Proper } \\
\text { vector }\end{array}$ & $\begin{array}{c}\text { Normalized } \\
\text { proper } \\
\text { vector }\end{array}$ & $\lambda_{\max }$ \\
\hline $\mathrm{F}_{1}$ & 1 & 1 & 5 & 5 & 5 & 5 & 9 & 9 & 1.36 & 0.27 & - & 3.87 & 0.32 & 2.64 \\
\hline $\mathrm{F}_{2}$ & 1 & 1 & 5 & 5 & 5 & 5 & 9 & 9 & 1.36 & 0.27 & - & 3.87 & 0.32 & 2.64 \\
\hline $\mathrm{F}_{3}$ & $1 / 5$ & $1 / 5$ & 1 & 1 & 1 & 1 & 5 & 5 & 0.58 & 0.115 & - & 1.00 & 0.08 & 0.66 \\
\hline $\mathrm{F}_{4}$ & $1 / 5$ & $1 / 5$ & 1 & 1 & 1 & 1 & 5 & 5 & 0.58 & 0.115 & - & 1.00 & 0.08 & 0.66 \\
\hline $\mathrm{F}_{5}$ & $1 / 5$ & $1 / 5$ & 1 & 1 & 1 & 1 & 5 & 5 & 0.58 & 0.115 & - & 1.00 & 0.08 & 0.66 \\
\hline $\mathrm{F}_{6}$ & $1 / 5$ & $1 / 5$ & 1 & 1 & 1 & 1 & 5 & 5 & 0.58 & 0.115 & - & 1.00 & 0.08 & 0.66 \\
\hline $\mathrm{F}_{7}$ & $1 / 9$ & $1 / 9$ & $1 / 5$ & $1 / 5$ & $1 / 5$ & $1 / 5$ & 1 & 1 & 0 & 0 & - & 0.26 & 0.02 & 0.18 \\
\hline $\mathrm{F}_{8}$ & $1 / 9$ & $1 / 9$ & $1 / 5$ & $1 / 5$ & $1 / 5$ & $1 / 5$ & 1 & 1 & 0 & 0 & - & 0.26 & 0.02 & 0.18 \\
\hline$\Sigma$ & & & & & & & & & 5.04 & 1.0 & $\mathbf{8 . 2 7}$ & 12.26 & 1.0 & $\mathbf{8 . 2 9}$ \\
\hline
\end{tabular}

Source: the authors' calculations

Table 4

Evaluation results of the consistency of the logistic matrices of pairwise comparison of the logistic potential elements

\begin{tabular}{|l|c|c|c|c|}
\hline \multirow{2}{*}{$\begin{array}{c}\text { Type of the logistic } \\
\text { strategy }\end{array}$} & \multicolumn{2}{|c|}{ Approximate calculations } & \multicolumn{2}{c|}{ Accurate calculations } \\
\cline { 2 - 5 } & Consistency index & Consistency ratio & Consistency index & Consistency ratio \\
\hline Cost minimization & 0.042 & 0.030 & 0.038 & 0.027 \\
\hline Diversification & 0.009 & 0.006 & 0.012 & 0.009 \\
\hline Specialization & 0.051 & 0.036 & 0.057 & 0.041 \\
\hline Logistic innovations & 0.087 & 0.062 & 0.128 & 0.092 \\
\hline
\end{tabular}

Source: the authors' calculations 
Table 5

Calculation results of the significance of logistic potential elements depending upon the selected logistic strategy

\begin{tabular}{|c|c|c|c|c|c|c|c|c|c|}
\hline \multirow{2}{*}{ Logistic strategy } & \multirow{2}{*}{ Evaluation methods } & \multicolumn{8}{|c|}{ Significance of the logistic potential elements } \\
\hline & & $\mathrm{F}_{1}$ & $\mathrm{~F}_{2}$ & $\mathrm{~F}_{3}$ & $\mathrm{~F}_{4}$ & $\mathrm{~F}_{5}$ & $\mathrm{~F}_{6}$ & $\mathrm{~F}_{7}$ & $\mathrm{~F}_{8}$ \\
\hline \multirow{3}{*}{ Cost minimization } & priority ranking & 0.200 & 0.200 & 0.127 & 0.127 & 0.127 & 0.135 & 0.042 & 0.042 \\
\hline & pairwise comparisons (approximate) & 0.316 & 0.316 & 0.082 & 0.082 & 0.082 & 0.082 & 0.021 & 0.021 \\
\hline & pairwise comparisons (accurate) & 0.270 & 0.270 & 0.115 & 0.115 & 0.115 & 0.115 & 0 & 0 \\
\hline \multirow{3}{*}{ Diversification } & priority ranking & 0.156 & 0.156 & 0.156 & 0.148 & 0.045 & 0.045 & 0.148 & 0.148 \\
\hline & pairwise comparisons (approximate) & 0.195 & 0.195 & 0.075 & 0.075 & 0.034 & 0.034 & 0.195 & 0.195 \\
\hline & pairwise comparisons (accurate) & 0.184 & 0.184 & 0.114 & 0.114 & 0.018 & 0.018 & 0.184 & 0.184 \\
\hline \multirow{3}{*}{ Specialization } & priority ranking & 0.179 & 0.179 & 0.179 & 0.029 & 0.108 & 0.108 & 0.111 & 0.108 \\
\hline & pairwise comparisons (approximate) & 0.280 & 0.280 & 0.111 & 0.018 & 0.055 & 0.055 & 0.055 & 0.146 \\
\hline & pairwise comparisons (accurate) & 0.241 & 0.241 & 0.152 & 0 & 0.061 & 0.061 & 0.061 & 0.183 \\
\hline \multirow{3}{*}{$\begin{array}{l}\text { Logistic } \\
\text { innovations }\end{array}$} & priority ranking & 0.150 & 0.084 & 0.150 & 0.150 & 0.150 & 0.084 & 0.150 & 0.084 \\
\hline & pairwise comparisons (approximate) & 0.164 & 0.055 & 0.164 & 0.164 & 0.164 & 0.055 & 0.164 & 0.072 \\
\hline & pairwise comparisons (accurate) & 0.142 & 0.070 & 0.162 & 0.162 & 0.162 & 0.070 & 0.162 & 0.070 \\
\hline
\end{tabular}

Source: the authors' calculations

Table 6

Calculation results of consistency evaluation of the significance of logistic potential elements

\begin{tabular}{|c|c|c|c|c|}
\hline \multirow{2}{*}{ Function } & \multicolumn{4}{|c|}{ Relative range r determined in terms of the strategy: } \\
\cline { 2 - 5 } & cost minimization & diversification & specialization & logistic innovations \\
\hline $\mathrm{F}_{1}$ & 0.442 & 0.224 & 0.435 & 0.143 \\
\hline $\mathrm{F}_{2}$ & 0.442 & 0.224 & 0.435 & 0.423 \\
\hline $\mathrm{F}_{3}$ & 0.421 & 0.696 & 0.463 & 0.076 \\
\hline $\mathrm{F}_{4}$ & 0.421 & 0.644 & 0.703 & 0.076 \\
\hline $\mathrm{F}_{5}$ & 0.421 & 0.835 & 0.710 & 0.076 \\
\hline $\mathrm{F}_{6}$ & 0.484 & 0.835 & 0.710 & 0.423 \\
\hline $\mathrm{F}_{7}$ & 0.996 & 0.271 & 0.738 & 0.076 \\
\hline $\mathrm{F}_{8}$ & 0.996 & 0.271 & 0.515 & 0.161 \\
\hline
\end{tabular}

Source: the authors' calculations

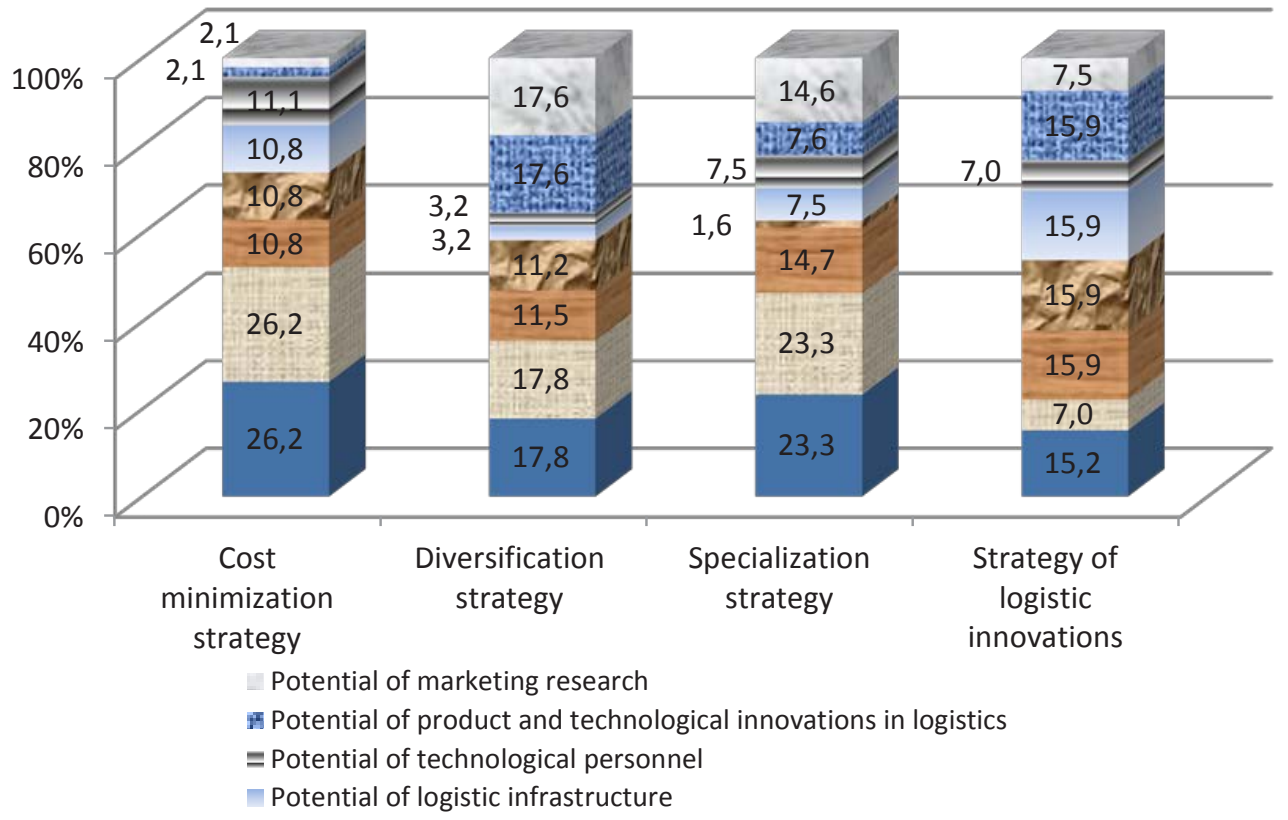

Figure 2. Average evaluation results of the significance of logistic potential elements

Source: the authors' calculations 


\section{Identification of logistics strategy type}

Research stage involves the comparison of relative values of cost share to form the logistic potential elements with the evaluation results of their significance. The stage involves the comparison of relative values of cost share to form the logistic potential elements with estimation results of their significance. The stage identifies such a ratio of the logistic potential elements in terms of their significance corresponding mostly to actual structure of total costs for its formation. Hence, an analytical expert can determine the type of logistics strategy, which the enterprise is capable of implementing within the current period. Determination of the compliance of current and perspective estimation results helps answer the question of whether the formed conditions correspond to the provision of the efficient implementation of the selected tendency of strategic changes.

The last stage of FCA implementation gives recommendations concerning the cost structure correction if the determined cost ratio of the logistic potential elements cannot provide formation of the required conditions to implement the selected logistic strategy over the next years. If so, it is required to start from the determination of the scheduled value of total costs to form logistic potential for the following period with their further distribution to changes in the elements according to their priority in terms of the developed profiles.

\section{Conclusions}

Quantitative evaluation of the conditions for the effective implementation of logistics strategy in the context of an enterprise has been considered as a certain applied stage of the process of strategic management of logistic potential making it possible to make following conclusions:

1. The current development stage limits enterprise possibilities to attract resources for a logistics strategy implementation; thus, they have to use at the most their own logistic potential involving eight components: a potential of managerial logistic staff; organizational potential; a potential of managerial innovations; transfer potential; a potential of logistic infrastructure; a potential of technologic personnel; a potential of product and technologic innovations in logistics; and a potential of market research. It is expedient to evaluate qualitatively certain components of the logistic potential with the use of functional-cost analysis.

2. The authors have substantiated the technique for qualitative evaluation of the logistic potential components to estimate relevance of internal environment of an enterprise to the selected strategy. The functional-cost analysis involves several stages, more specifically: preparatory stage, information stage, analytical stage, study stage, and recommendation one.

3. A type of logistic strategy, implemented by an enterprise (able to implement), is determined according to the comparison results of a logistic potential structure (identified on the estimated significance of its certain elements) and structure of total expenditures connected with its formation. That has made it possible to specify managerial decisions as for the cost structure planning to form its elements.

Further studies should be intended to evaluate optimizing logistics potential which high level means an efficient organization of material and financial flows, and hence capability of an enterprise to use productively the formed conditions to implement the selected logistic strategy.

\section{References:}

Baranets, G. (2016). Obgruntuvannja vyboru logistychnoji strategjii promyslovogo pidpryjemstva [Grounding the choice of logistic strategy an industrial enterprise]. Ekonomichnyi dyskurs, 3, 88-98. (in Ukrainian)

Beshelev, S., Hurvich, F. (2008). Matematiko-statisticheskie metody jekspertnyh ocenok [Mathematical and Statistical Methods of Expert Evaluation]. Moskva: Finansyi i statistika. (in Russian)

Dybskaja, V., Zajcev, E., Sergeev, V., Sterligova, A. (2008). Logistika. Polnyj kurs MBA [Logistics: Complete Course MBA]. Moskow: Jeksmo. (in Russian)

Krykavskyi, Ie. (2004). Logistyka. Osnovy teorii [Logistics. Theoretical Framework]. Lviv: NU «Lvivska politehnika», «Intelekt-zahid». (in Ukrainian)

Nikul,E. (2012). Algoritm analiza matric parnyh sravnenij s pomoshhju vychislenija vektorov prioritetov [Algorithm of analysis of pairwise comparisons matrices using the priority vectors calculations]. Izvestiya YUFU. Tehnicheskie nauki, 2, 241-247. (in Russian)

Saaty, T. L. (2008). Decision making with the analytic hierarchy process, Int. J. Services Sciences, 1, 83-98.

Senchenko, S. (2011). Ponjatija, koncepcii i metodiki funkcionalno-stoimostnogo analiza na sovremennom jetape razvitija jekonomiki [Notions, Conceptions and Methods of Function and Value Analysis at the Modern Stage of Economics Development]. Izvestiya Yujnogo federalnogo universiteta, 11, 70-74. (in Russian)

Sergeev, V. (2013). Korporativnaja logistika v voprosah i otvetah [Corporate Logistics in Questions and the Answers]. Moskow: INFRA-M. (in Russian)

Stock, J. R., Lambert, Douglas, M. (2005). Strategicheskoe upravlenie logistikoy [Strategic Logistics Management]. Moskow: INFRA-M. (in Russian)

Waters, D. (2009). Supply Chain Management: An Introduction to Logistics. 2nd ed. Hampshire: Palgrave Macmillan. 